\title{
Serge Tcherkézoff, Mauss à Samoa. Le holisme sociologique et l'esprit du don polynésien
}

Aix-Marseille, Pacific-credo Publications, 2016, 396 p.

\section{Benoît Vermander}

\section{(2) OpenEdition}

\section{Journals}

Édition électronique

URL : http://journals.openedition.org/assr/28356

DOI : $10.4000 /$ assr.28356

ISSN : $1777-5825$

Éditeur

Éditions de l'EHESS

Édition imprimée

Date de publication : 31 décembre 2016

Pagination : 396

ISSN : 0335-5985

Référence électronique

Benoît Vermander, « Serge Tcherkézoff, Mauss à Samoa. Le holisme sociologique et l'esprit du don polynésien », Archives de sciences sociales des religions [En ligne], 176 | octobre-décembre 2016, mis en ligne le 20 juillet 2017, consulté le 24 septembre 2020. URL : http://journals.openedition.org/assr/ 28356 ; DOI : https://doi.org/10.4000/assr.28356

Ce document a été généré automatiquement le 24 septembre 2020.

(c) Archives de sciences sociales des religions 


\section{Serge Tcherkézoff, Mauss à Samoa. Le holisme sociologique et l'esprit du don polynésien}

Aix-Marseille, Pacific-credo Publications, 2016, 396 p.

\section{Benoît Vermander}

\section{RÉFÉRENCE}

Serge Tcherkézoff, Mauss à Samoa. Le holisme sociologique et l'esprit du don polynésien, Aix-Marseille, Pacific-credo Publications, 2016, 396 p.

Encore une lecture de L'Essai sur le Don ? Oui, mais nourrie et orientée par l'examen d'un cas seulement brièvement mentionné par Mauss, un cas dont l'auteur va faire la clé de sa propre analyse de «l'esprit » et de « l'obligation » du don. Serge Tcherkézoff, auteur d'études sur (notamment) Le mythe occidental de la sexualité polynésienne et L'invention française des "races » et des régions de l'Océanie, étudie ici avec grande minutie le dossier des tissus sacrés rituellement donnés et échangés à Samoa. Dans L'Essai, le cas des "nattes blasonnées de Samoa » fait l'objet de la brève première partie du premier chapitre. L'exemple samoan introduit le concept d'« objets à mana» (ou "propriététalisman ») ainsi que les types de dons auxquels ces objets donnent lieu. Chez Mauss, le cas samoan s'appuie sur un dossier assez mince ; immédiatement après sa présentation, l'exposé du cas maori va détailler la logique de circulation obligatoire du sacré telle que Mauss la conçoit. Mais c'est bien l'exemple samoan qui d'abord distingue les types d'objets et de dons aptes à constituer une prestation totale. L'Essai ne s'intéresse pas à l'échange comme catégorie universelle, mais au don des objets sacrés, symboles de collectivité, véhicules de mana, ces dons particuliers qui permettent de faire des prestations totales (p. 129-135).

2 L'ouvrage est divisé en deux grandes parties. La première est consacrée à la socioanthropologie générale de Marcel Mauss et à ses relectures, d'abord et avant tout celle 
conduite par Lévi-Strauss. De l'aveu même de l'auteur, cette partie est fondée sur un cours professé essentiellement en 1995, et un lecteur familiarisé avec ces textes célèbres pourrait donc en faire l'économie. Néanmoins, la minutie de la lecture comme le retour critique aux sources de Mauss font tout l'intérêt du commentaire ici proposé. Il dévoile la cohérence de la pensée maussienne, de sa gestation à son développement ; en contraste avec d'autres interprétations, il insiste sur le fait que «c'est la raison de l'obligation de rendre qui demeure la question unique de l'origine du don» (p. 69); l'horizon ouvert par L'Essai est ainsi résumé: "Certaines sociétés montrent à quel point le vocabulaire et la matière du sacrifice d'une part et de l'échange d'autre part peuvent devenir un seul et même système (ou l'avoir été depuis les premières formes d'échange » (p. 77).

3 Dans cette première partie, le chapitre 9 est consacré à l'étude d'une "généralisation fautive » de Mauss : le caractère dualiste des dons à Samoa a été transposé par lui dans une opposition entre objets de don masculins et féminins. L'auteur montre les raccourcis auxquels Mauss s'est livré dans la lecture de ses sources. Il privilégie à l'inverse une lecture tripartie (hommes, femmes, entité surhumaine) du processus d'échange et de son rapport à la fécondation: "Le travail du don de vie par la manipulation des objets sacrés est une collaboration - avec toutes les asymétries internes possibles - entre les fils et les filles des ancêtres»(p.146). Le point est d'importance, car il permet par la suite à l'auteur de se distancer des analyses d'Annette Weiner et de leur reprise par Maurice Godelier. Chez ces derniers, la classification des tissus sacrés (ou «nattes fines») en biens féminins les amène finalement à considérer leur circulation comme marquée du sceau paradoxal de l'« inaliénable", advenant dans un monde où on donnerait tout en conservant. Les nattes fines, écrit Tcherkézoff, font bien référence à un point fixe, au sacré, moteur social de l'échange, mais les seules nattes à ne pas circuler ne sont autres que les linceuls funéraires: la première nappe ayant servi à envelopper le premier ancêtre, « les femmes de la famille tissent à chaque génération des nattes qui sont en quelque sorte la réplique de la première nappe » (p. 347).

4 La deuxième partie étudie avec luxe de détails les nattes fines de Samoa, et la façon dont ce dossier ethnographique éclaire la question du don polynésien. Elle situe d'abord les nattes fines à l'intérieur du système de fabrication d'un matériau léger pour envelopper choses et personnes - pièces de tapa ou tissages de lanière. Les tissus consacrés comprennent les nattes fines et certains tapas (mais ce sont les premières qui sont au centre et du système et de l'étude). Les récits ethnographiques mettent en lumière le rôle de «recouvrement de la vie » joué par les nattes fines (l'auteur jouant sur l'ambivalence sémantique du terme de «recouvrement » en français), rôle qui en fait des «talismans life-giver» (p. 225). Les légendes recueillies confirment l'analyse ; elles montrent notamment comment les nattes en arrivent à symboliser l'enveloppe, la matrice, qui donne naissance aux deux sexes humains par le rapprochement des dieux mâles et de la femme primordiale (p. 266). L'interprétation est encore renforcée par l'analyse des rites de défloration manuelle, « son traitement cérémoniel public [n'étant] pas tant une question d'honneur masculin pour le père ou le fiancé qu'une procédure nécessaire au travail de reproduction humaine » (p.282). Le traitement cérémoniel commence avec la défloration au-dessus d'une natte fine et continue avec la mise au monde et la présentation de l'enfant. «Les Samoans ont conçu l'enveloppement- 
recouvrement par les nattes fines comme un travail, rituel et mythique, sur la vie " (p. 287).

5 L'analyse se poursuit en considérant les tissus sacrés comme «natte monnaie »: les nattes données «recouvrent» le don initial. L'histoire des nattes fines (talismans, indicatrices de généalogie, et désormais anonymes, associées aux offrandes monétaires) illustre les étapes de la création de la monnaie telles que décrites par Mauss, à condition de substituer ici une approche partiellement synchronique à une succession historique trop systématique.

La conclusion souligne à quel point l'exemple samoan illustre le caractère total qui caractérise certains dons, et insère l'étude dans son contexte malayo-polynésien. Elle est fondée pour partie sur nombre de témoignages oraux, qu'elle nous semble " entendre » avec sensibilité et justesse. Le don renforce la vie : «L'“esprit du don", c'est le bonheur de donner et la capacité à créer la vie» (p. 315). La gratuité s'associe ici avec la nécessité : "Moins on donne à autrui, moins on donne à voir aux autres et moins on s'attribue à soi-même de la valeur généalogique » (p. 317). Dans cette configuration, le tissu sacré polynésien "sacralise " en donnant une nouvelle vie à qui ou quoi il enveloppe. Parallèlement, lorsque le donateur le déroule sur la voie, il devient le chemin des dieux. De façon privilégiée, la fiancée couverte de nattes est elle-même canal du divin. Plus généralement, en enveloppant les forces brutes du sacré, on opère la transformation d'une puissance dangereuse en une proximité que l'on pourra toucher sans enfreindre de tabous. Le processus de recouvrement/dévoilement du sacré " cache la source de pouvoir de vie, mais, de ce fait, en donne à voir les bienfaits " (p. 341). En conséquence, la manipulation des objets symboliques « est ce qui fait la vie même du groupe" (p.349). Aujourd'hui encore, se soustraire à l'échange de pareils objets, se couper du système général qu'ils organisent, c'est courir le risque de ne plus appartenir à l'ensemble social duquel dépend l'enracinement dans la terre et la vie.

7 La lecture de l'ouvrage procure le double plaisir de la découverte progressive d'un riche dossier ethnographique et de l'entrée dans une entreprise théorique ancrée dans la minutieuse interprétation de textes fondateurs. Il illustre avec brio ce que recouvre le terme de «fait social total» tout en traquant les malentendus et abus qui marquent encore son usage. Marqué de bout en bout par une grande prudence factuelle et méthodologique, il confirme en même temps à quel point les hypothèses formulées dans L'Essai sur le don restent fécondes. 